\title{
Effect of Da-Cheng-Qi Decoction on the Repair of the Injured Enteric Nerve-Interstitial Cells of Cajal-Smooth Muscle Cells Network in Multiple Organ Dysfunction Syndrome
}

\author{
Mu-Cang Liu, Ming-Zheng Xie, Bin Ma, and Qing-Hui Qi \\ Department of General Surgery, The First Affiliated Hospital of Dalian Medical University, Liaoning 116011, China \\ Correspondence should be addressed to Qing-Hui Qi; qinghui_qi@126.com
}

Received 27 June 2014; Revised 18 October 2014; Accepted 21 October 2014; Published 13 November 2014

Academic Editor: Karl Wah-Keung Tsim

Copyright (C) $2014 \mathrm{Mu}$-Cang Liu et al. This is an open access article distributed under the Creative Commons Attribution License, which permits unrestricted use, distribution, and reproduction in any medium, provided the original work is properly cited.

\begin{abstract}
Wistar rats were randomly divided into control group, multiple organ dysfunction syndrome (MODS) group, and Da-ChengQi decoction (DCQD) group. The network of enteric nerves-interstitial cells of Cajal- (ICC-) smooth muscle cells (SMC) in small intestine was observed using confocal laser scanning microscopy and transmission electron microscopy. The results showed that the numbers of cholinergic/nitriergic nerves, and the deep muscular plexus of ICC (ICC-DMP) and connexin43 (Cx43) in small intestine with MODS were significantly decreased. The network integrity of enteric nerves-ICC-SMC was disrupted. The ultrastructures of ICC-DMP, enteric nerves, and SMC were severely damaged. After treatment with DCQD, the damages were repaired and the network integrity of enteric nerves ICC-SMC was significantly recovered. In conclusion, the pathogenesis of gastrointestinal motility dysfunction in MODS in part may be due to the damages to enteric nerves-ICC-SMC network and gap junctions. The therapeutic mechanism of DCQD in part may be that it could repair the damages and maintain the integrity of enteric nerves ICC-SMC network.
\end{abstract}

\section{Introduction}

Multiple organ dysfunction syndrome (MODS) is the main cause of the death of patients with abdominal surgical diseases, which are characterized by hypermetabolizability, hypercirculation, immoderate, and out of controlled inflammatory response and organ dysfunction [1-3]. Its etiology is various, its pathogenesis is elusive, and its mortality is very high.

Studies have found that gastrointestinal (GI) tract is the key organ to originate and trigger systemic inflammation response syndrome (SIRS) and MODS $[4,5]$. The condition of GI function is thought to be the criterion of evaluating the prognosis of critical patients $[6,7]$. In the treatment of GI dysfunction, the recovery of GI motility is very important. Improving the recovery of GI motility could effectively prevent MODS from deteriorating to multiple organ failure. So, it is necessary to investigate the pathogenesis of GI motility dysfunction and look for effective treatments for MODS $[8,9]$.
Interstitial cells of Cajal (ICC) show a highly branched morphology and form unique network in GI tract. ICC serve as electrical pacemakers, active propagation pathways for slow waves, and mediators of enteric motor neurotransmission. They play an important role in generating and regulating of GI motility. Enteric nerves system (ENS), ICC, and smooth muscle cells (SMC) connect to form a network structure, which is the basic functional unit of GI motility [10]. Gap junctions connect ICC to ICC, ICC to SMC, and SMC to SMC [11-14]. Connexin $(\mathrm{Cx})$ is the basic structural and functional proteins that form gap junction channel. Studies have shown that, in GI motility dysfunction diseases, there is abnormality or decrease in the number of ICC $[15,16]$, or decrease in neurotransmission of ENS-ICC-SMC network [17-19], or abnormal expression of $\mathrm{Cx}$ [20].

In clinical practice, Chinese researchers have found that purgative therapy have a good effect on prevention and treatment of MODS. Da-Cheng-Qi decoction (DCQD) is compound preparation, composed of Rhubarb, Mirabilite, 
Fructus Aurantii Immaturus, and Mangnolia officinalis. DCQD has been used as purgative for nearly two thousand years in China. Researchers have found it was very effective in promoting the recovery of GI motility [21-23]. However, the mechanism is not fully understood.

In this study, the rat models with MODS induced by bacterial peritonitis were investigated, the morphological changes of ENS-ICC-SMC network in rats were observed, and the therapeutic effect of DCQD was investigated.

\section{Materials and Methods}

2.1. Materials. One hundred adult Wistar rats (200 g-250 g), half male and half female, were provided by experimental animal center of Dalian Medical University. Escherichia coli (E. coli) strain was provided by clinical laboratory of the First Affiliated Hospital of Dalian Medical University. DaCheng-Qi granules (batch number: 20130108) were provided by pharmaceutical factory of Tianjin Nankai Hospital, each dose drug was made of crude drug of $12 \mathrm{~g}$ of Rhubarb, $6 \mathrm{~g}$ of Mirabilite, $9 \mathrm{~g}$ of Fructus Aurantii Immaturus, and $9 \mathrm{~g}$ of Magnolia officinalis. Each dose drug was added into $36 \mathrm{~mL}$ distilled water and dissolved into liquid containing $100 \%$ crude drugs $(1 \mathrm{~g} / \mathrm{mL})$.

2.2. Animal Grouping and Model Preparation. According to the random number table method, rats were grouped as follows: control group, twenty rats, each rat was intraperitoneally infused with $1 \mathrm{~mL}$ saline; MODS group, forty rats, each rat was intraperitoneally infused with $1 \mathrm{~mL} E$. coli suspensions to establish the rat model of MODS; the DCQD group, forty rats, each rat was intraperitoneally infused with $1 \mathrm{~mL}$ E. coli suspensions to establish the rat model of MODS. In the same day, each rat was given DCQD by gavage, two times/days, each time $1 \mathrm{~mL} / 100 \mathrm{~g}$.

The study protocol was approved by the ethics committee of the First Affiliated Hospital of Dalian Medical University.

Diagnostic criteria of rat model of MODS [24]: respiratory distress and respiratory frequency $\geqslant$ two times contrast value; tachycardia and heart rate $\geqslant$ two times contrast value; abdominal bloating and bowel sounds are weakened or disappeared; blood bilirubin or glutamic-pyruvic transaminase $\geqslant$ two times contrast value.

2.3. The Deep Muscular Plexus of ICC (ICC-DMP) and Cholinergic/Nitrergic Nerves-ICC Network in Intestinal Tissues Using Confocal Laser Scanning Microscopy. Forty-eight hours, respectively, after operation, the rats were killed with anesthesia. Ten-centimeter small intestine near pylorus was removed, cut into $1-2 \mathrm{~cm}$ fragments, fixed on zamboni liquid, and placed in refrigerator, $4^{\circ} \mathrm{C}$, overnight. Dissected with anatomic microscope, the mucosa and submucosa as one layer were striped and complete intestinal muscularis was retained.

In order to investigate ICC-DMP and cholinergic nervesICC network, double stained with c-Kit and vesicular acetylcholine transporter (VAChT) immunohistochemistry according to Nemeth's method [25]: after finishing the wholemount preparation, (1) the specimens were incubated in $0.5 \%$
Triton-X in $0.05 \mathrm{~mol} / \mathrm{L}$ Tris- $\mathrm{HCl}$ buffer ( $\mathrm{pH}$ 7.6) solution at $37^{\circ} \mathrm{C}$ for 4 hours; (2) after rinsing twice in PBS, the specimens were incubated 1 hour at room temperature in $1 \%$ BSA to prevent a specific linking; (3) after rinsing twice in PBS, the tissues were incubated 48 hours at $4^{\circ} \mathrm{C}$ in goat anti-rat VAChT polyclonal antibody (Santa Cruz, Biotech, USA); (4) the tissue samples were again rinsed twice in PBS and incubated with Texas Red-labeled donkey anti-goat IgG antibody (Santa Cruz, Biotech, USA) for 2 hours at room temperature; (5) after rinsing twice in PBS, the tissues were incubated 48 hours at $4^{\circ} \mathrm{C}$ in rabbit anti-rat c-kit polyclonal antibody (c-19, Santa cruz, Biotech, USA); (6) the whole tissue specimens were rinsed twice and incubated 2 hours at $4^{\circ} \mathrm{C}$ away from light in FITC-mouse anti-rabbit IgG antibody (Biotech, USA); (7) the tissue specimens were embedded into fluorescence mounting medium and investigated with confocal laser scanning microscopy.

In order to investigate ICC-DMP and nitrergic nervesICC network, it was double stained with C-Kit and neuronal nitric oxide synthase (nNOS) immunohistochemistry according to Nemeth's method [25]. It was the same way as above, but we added goat anti-rat nNOS polyclonal antibody (Santa Cruz, Biotech, USA) instead of VAChT polyclonal antibody in step (3).

Control group added antibody diluent only instead of antibody in steps (3) and (5).

Specimens were observed using a TCS-SP2 laser scanning confocal microscope (Leica, Germany) with immersion objectives $(\times 40$ numerical aperture 1.3$)$. Tissue specimens were excited using a krypton/argon laser with excitation and barrier filters set for individual fluorophores according to their specific excitation-emission spectra (FITC $=494 \mathrm{~nm}$ and Texas Red $=595 \mathrm{~nm}$ ). The emitted light was detected by a photomultiplier tube and converted via an analog-todigital converter into a digital pixelated image. The detection pinhole was set for use with different objectives accordingly. $\mathrm{C}-\mathrm{Kit}$ positive fluorescence was green and VAChT positive fluorescence was red. Three specimens were observed in each group and three high magnification visions were observed randomly in each specimen. Three-dimensional images reconstruction and fluorescence quantitative were performed by Leica confocal software.

2.4. Cx43 in Intestinal Tissues Using Light Microscopy. The same specimens of small intestine were cut into $1 \mathrm{~cm}$ long fragments, fixed in formaldehyde, and placed in refrigerator, $4^{\circ} \mathrm{C}$, overnight. Thereafter, $2 \mathrm{~mm}$ long tissue was removed, dehydrated using graded ethanol, dewaxed using dimethyl benzene, and cut to serial sections, $5 \mu \mathrm{m}$ thick, using Leitz1512 slicer. Tissue biopsies were dried for 4 hours at $60^{\circ} \mathrm{C}$ in oven. (1) they were dewaxed by dimethyl benzene and dehydrated using graded ethanol; (2) they were put in hydrogen peroxide methanol to block endogenous peroxidase; (3) they were put in $0.1 \mathrm{~mol} / \mathrm{L}$ citrate buffer solution (PH6.0), boiling for 20 minutes, for antigen repair; (4) after rinsing three times in PBS, they were incubated with normal goat serum for 20 minutes at room temperature; (5) after removing excess serum, they were incubated with mouse anti-rat connexin 43 monoclonal antibody (CXN-6, Santa Cruz, Biotech, USA) 


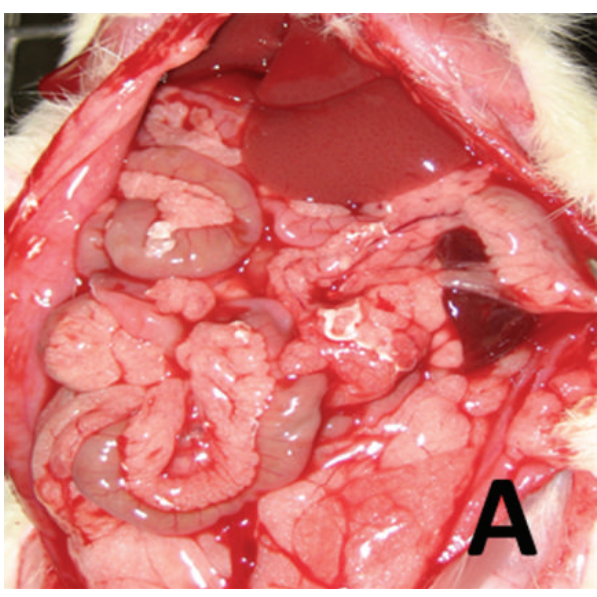

(a)

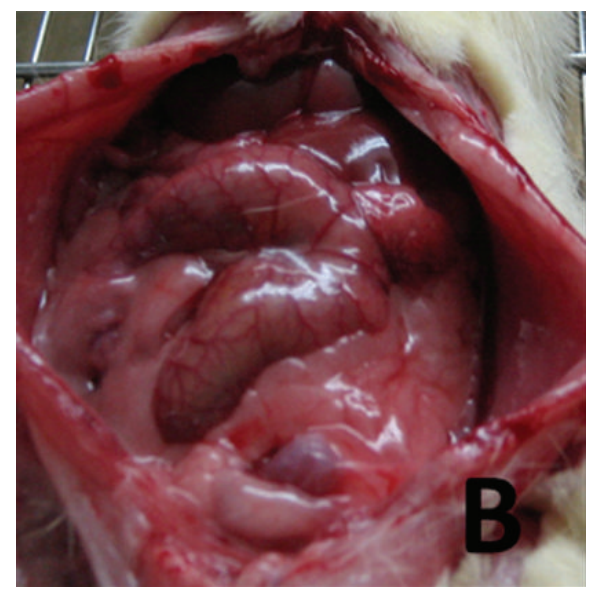

(b)

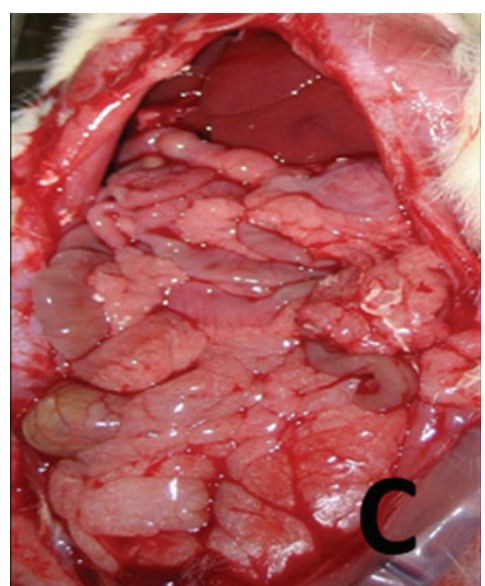

(c)

FIGURE 1: GI gross specimen. (a) It shows GI gross specimen of control group; (b) it shows GI gross specimen of MODS group; (c) it shows GI gross specimen of DCQD group.

(diluted to $1: 200$ ) and placed in refrigerator, $4^{\circ} \mathrm{C}$, overnight; (6) after rinsing three times in PBS, they were incubated with biotin-labeled sheep anti-mouse $\operatorname{IgM}$ antibody for 30 minutes at room temperature; (7) after rinsing three times in PBS, they were incubated with $\mathrm{ABC}$ kit for 30 minutes at room temperature; (8) they were colored by DAB for 58 minutes; (9) they were stained with hematoxylin for 30 seconds; (10) they were blued with water for 30 minutes; (11) they dehydrated using graded ethanol; (12) vitrification was by dimethyl benzene; (13) they were mounted using neutral gum; (14) in control group, antibody diluent was added only instead of antibody in steps (5).

Tissue biopsies were observed using Nikon light microscope. Six specimens in each group and five high magnification visions in each specimen were observed randomly. Images were analyzed according to Nemeth's method [25].

\subsection{Cx43 in Small Intestinal Muscle Strips Using Transmission} Electron Microscopy. In the same specimens of small intestine, $10 \mathrm{~cm}$ small intestine near pylorus was removed and cut into $1 \mathrm{~mm} \times 2 \mathrm{~mm}$ fragments. (1) Tissues were laid flat on filter paper, fixed in $4 \%$ glutaraldehyde, and rinsed in $0.1 \%$ phosphate buffer. Thereafter, they were fixed in $1 \%$ osmium tetroxide and rinsed in $0.1 \%$ phosphate buffer, (2) they were dehydrated using graded ethanol; (3) after fixed in osmic acid, they were dehydrated using graded ethanol, substituted using epoxypropane, and embedded using Epon812; (4) in semiultrathin sections, $1 \sim 2 \mu \mathrm{m}$, they stained with $2 \%$ toluidine blue and observed using light microscope. Distinguishing the location of mucosa, submucosa, circular muscularis, and longitudinal muscularis, the myenteric plexus and deep nerve plexus were made into ultrathin section; (5) ultrathin sections (50-70 nm thick) were put on copper reseau with 200 or 400 holes. (6) after staining with uranyl acetate, stained with citrate; (7) tissue biopsies were observed using JEM-2000EX transmission electron microscope. The images collection and statistical analysis were completed.
2.6. Statistical Analysis. The data was analyzed using a commercial software package (SPSS 13.0). Data of ICC-DMP and ENS-ICC network in intestinal tissues were expressed as mean \pm standard deviation, $t$-test was applied for difference comparison among each group, and $P<0.05$ denoted the difference possessing statistical significance. Data of Cx43 in intestinal tissues using light microscopy was analyzed by rank sum test, and $P<0.05$ denoted the difference possessing statistical significance.

\section{Results}

Forty-eight hours later, in control group, all 20 rats survived; in MODS group, twenty-four hours later, 30 rats reached the criterion of MODS and, forty-eight hours later, 21 rats died. In DCQD group, twenty-four hours later, 29 rats reached the criterion of MODS and, forty-eight hours later, 12 rats died. There was no difference in occurrence time and incidence of MODS between MODS group and DCQD group. But, we found that the rats in MODS group ate less than DCQD group. The mortality in DCQD group was lower than that in MODS group (41.4\% versus $70.0 \%$, Chi-square test, $P<$ 0.05).

3.1. GI Gross Specimen. Control group (Figure 1(a)) shows the GI tract was normal in appearance: pink, no adhesion, and regular bowel movements could be seen.

MODS group (Figure 1(b)) shows the GI tract was extremely distended and swelling, most of the bowel was dark, and there was bloody ascites in some rats. Moreover, we found that there were dark bloody liquid in lumen, bleeding spots and necrosis on intestinal mucosa, bleeding spots on great omentum, and a lot of exudation in abdominal cavity. We also found that bowel movements disappeared.

DCQD group (Figure 1(c)) shows the GI tract was red, lightly distended, and swelling. Though there was a small amount of pale yellow liquid in lumen and a small amount of exudation in abdominal cavity, there were no bloody ascites. Moreover, bowel movements were nearly normal. 


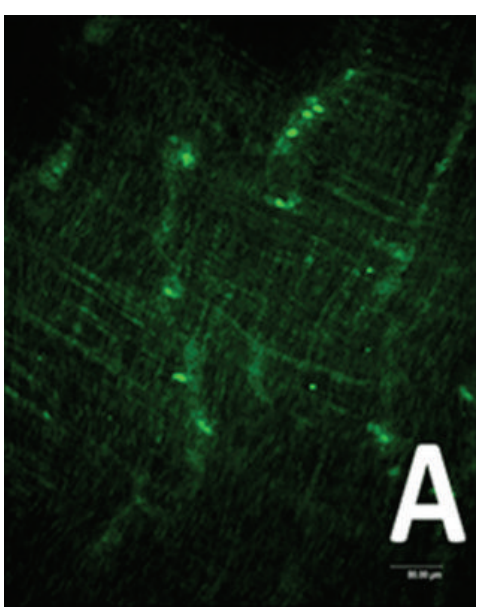

(a)

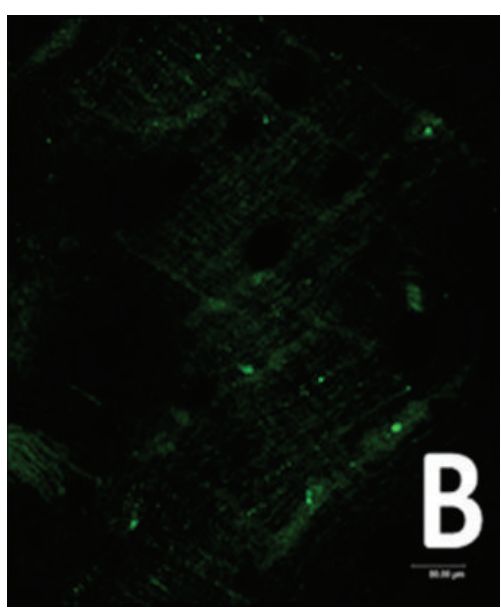

(b)

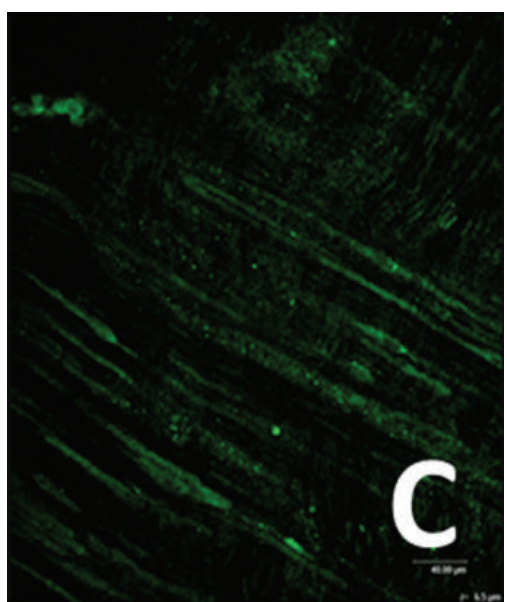

(c)

FIgURE 2: ICC-DMP using confocal microscopy. (a) Control group shows ICC-DMP connected to each other and formed network (Ruler: $80 \mu \mathrm{m}$ ); (b) MODS group shows there was an obvious decrease in numbers of ICC and synapses. Moreover, network integrity was damaged. IOD was also markedly decreased (ruler: $80 \mu \mathrm{m}$ ); (c) DCQD group shows ICC and synapses of ICC were more than MODS group, maintaining net structure (ruler: $40 \mu \mathrm{m}$ ).

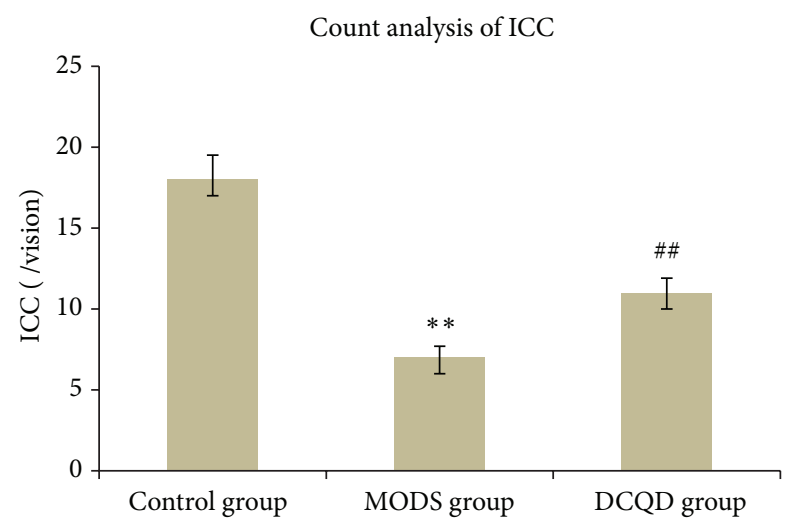

Figure 3: Count analysis of ICC. Three specimens in each group and three high magnification visions in each specimen were observed randomly. Compared with control group, $n=9,{ }^{* *} t=8.295, P<$ 0.01; compared with MODS group, $n=9,{ }^{\# \#} t=4.041, P<0.01$.

3.2. ICC-DMP Using Confocal Microscopy. Control group (Figure 2(a)) shows ICC-DMP were spindle-shaped cells with 2-3 synapses, these cells connected to each other by synapses, and they formed network structure.

MODS group (Figures 2(b), 3, and 4) shows that not only there was an obvious decrease in numbers of ICC and synapses, but network integrity was damaged. Integrated optical density (IOD) of ICC was also markedly decreased.

DCQD group (Figures 2(c), 3, and 4) shows the numbers of ICC and synapses of ICC were more than MODS group and ICC formed network structure. IOD of ICC was also markedly elevated and compared with MODS group.

3.3. Cholinergic/Nitrergic Nerves-ICC Network Using Confocal Microscopy. Control group (Figures 5(a) and 6(a)) shows the dense c-Kit-positive cellular network (ICC-DMP), located

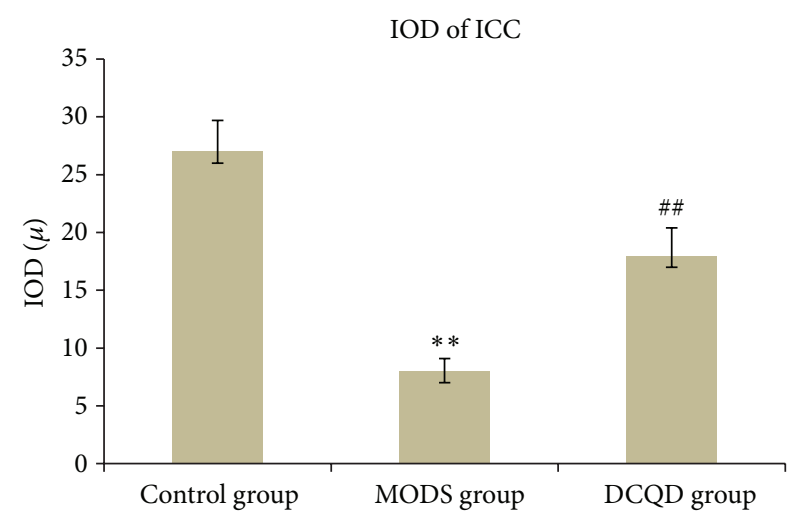

FIgURE 4: IOD of ICC. Three specimens in each group and three high magnification visions in each specimen were observed randomly. Compared with control group, $n=9,{ }^{* *} t=6.536$, $P<0.01$; compared with MODS group, $n=9,{ }^{\# \#} t=3.917, P<0.01$.

between the longitudinal and circular muscularis and at the innermost part of the circular muscularis, and intermingled with the myenteric plexus. Between the circular muscle fibers, there was abundance of VAChT/nNOS-positive nerve fibers and c-Kit-positive cellular network run parallel with the muscle fibers. We also found that the VAChT/nNOS-positive myenteric plexus was surrounded by a reticular network of c-Kit-positive ICC.

MODS group (Figures 5(b), 6(b), 7, and 8) shows ICC and cholinergic/nitrergic nerve fibers were significantly reduced, the connections between nerves and ICC were reduced or disappeared, and cholinergic/nitrergic nerves-ICC network integrity was damaged significantly. IOD of ICC and nerve fibers was markedly decreased.

DCQD group (Figures 5(c), 6(c), 7, and 8) shows ICC, cholinergic/nitrergic nerve fibers, and neuronal connections 


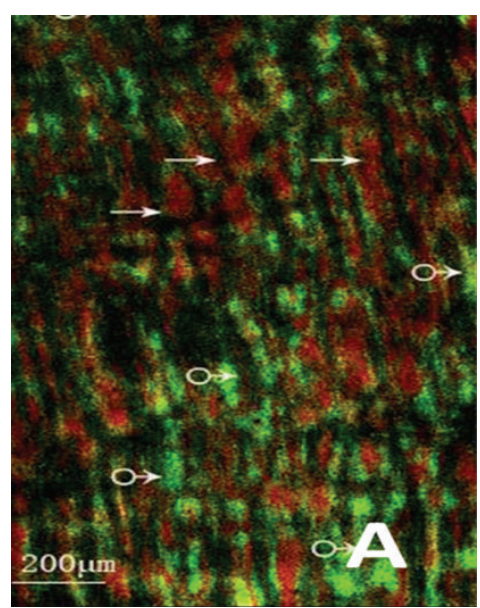

(a)

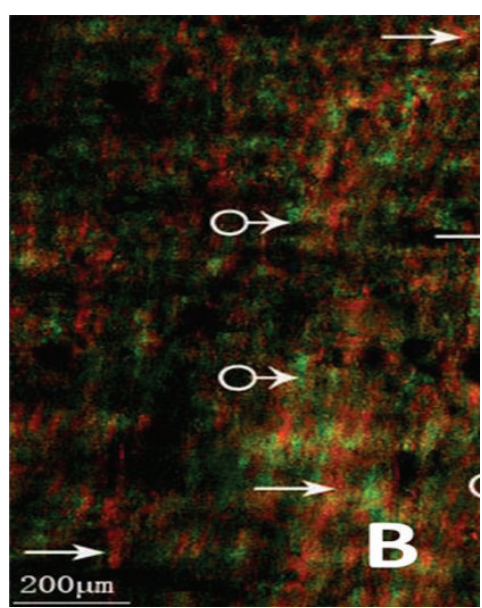

(b)

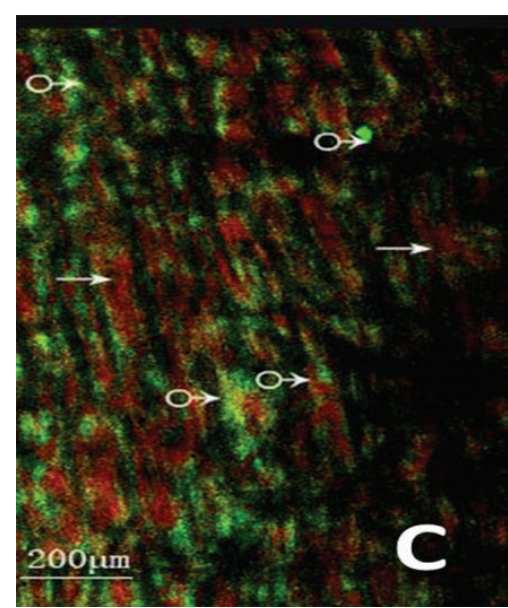

(c)

FIGURE 5: Cholinergic nerves-ICC network using confocal microscopy. (a) It shows cholinergic nerves-ICC network of control group ( $\rightarrow$ : nerve fiber, ${ }^{\star}$ : ICC (ruler: $200 \mu \mathrm{m}$ ); (b) it shows cholinergic nerves-ICC network of MODS group ( $\rightarrow:$ nerve fiber, $\delta^{\star}:$ ICC). Nerve fibers and ICC were significantly reduced and the nerves-ICC network integrity was damaged (ruler: $200 \mu \mathrm{m}$ ); (c) it shows cholinergic nerves-ICC network of DCQD group $\left(\rightarrow:\right.$ nerve fiber, ${ }^{*}$ : ICC). Nerve fibers and neuronal connections were more than MODS group, maintaining net structure (ruler: $200 \mu \mathrm{m}$ ).

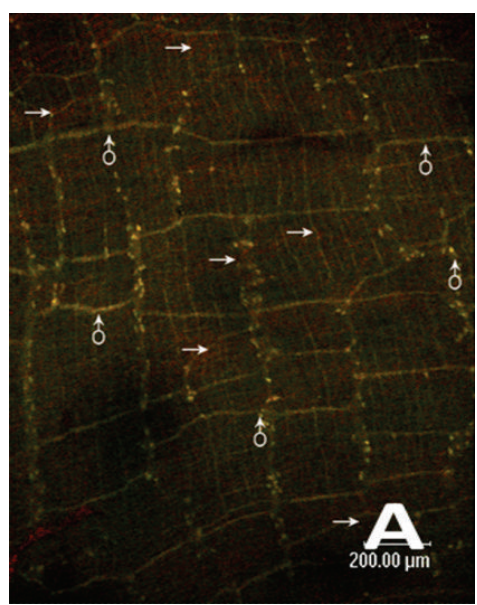

(a)

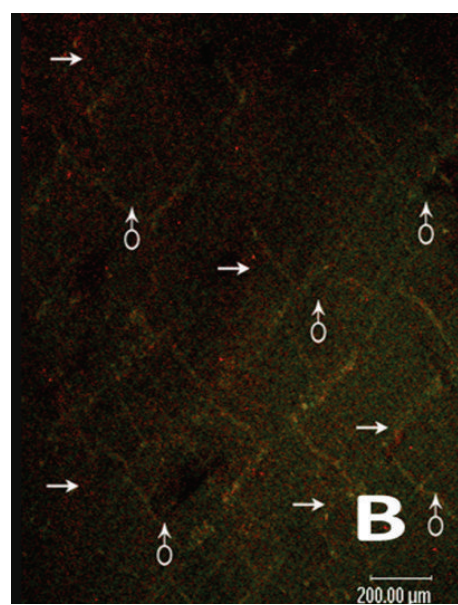

(b)

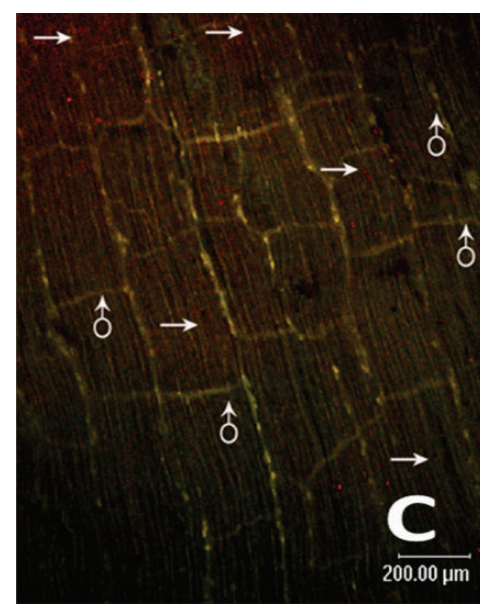

(c)

FIGURE 6: Nitrergic nerves-ICC network using confocal microscopy. (a) It shows nitrergic nerves-ICC network of control group ( $\rightarrow:$ nerve fiber, o: ICC) (ruler: $200 \mu \mathrm{m})$; (b) it shows nitrergic nerves-ICC network of MODS group ( $\rightarrow$ : nerve fiber, o $^{*}$ ICC). Nerve fibers and ICC were significantly reduced and the nerves-ICC network integrity was damaged (ruler: $200 \mu \mathrm{m})$; (c) it shows nitrergic nerves-ICC network of DCQD group ( $\rightarrow$ : nerve fiber, o: ICC). Nerve fibers and neuronal connections were more than MODS group, maintaining net structure (ruler: $200 \mu \mathrm{m}$ ).

were more than MODS group and formed network structure. IOD of ICC and nerve fibers was also markedly elevated, compared with MODS group.

\subsection{Ultrastructures of ICC Using Conventional Electron} Microscopy. Control group (Figure 9(a)) shows ICC were shuttle type, nucleus was big, and oval and chromatins structure was clear. There were abundant mitochondria, smooth endoplasmic reticulum, ribosomes, and few of rough endoplasmic reticulum in ICC, and Golgi apparatus were small. There was intact basal membrane.

MODS group (Figure 9(b)) shows nucleus shriveled, and the number of organelles was decreased significantly. We also found mitochondria were distorting and swelling, and endoplasmic reticulum was dilated. Moreover, we found the basal membrane was incomplete.

DCQD group (Figure 9(c)) shows nucleus was normal and the number of organelles was more than MODS group. Only a few of mitochondria were swelling and a few of endoplasmic reticula were dilated. Moreover, we found the basal membrane was almost complete.

3.5. Cx43 in Intestinal Tissues Using Light Microscopy. Control group (Figure 10(a)) shows immunoreactive products of $\mathrm{Cx} 43$ were tan and mainly distributed in the cytomembrane and cytoplasm. In small intestinal muscularis, Cx43 was 
TABLE 1: Cx43 in small intestinal muscularis.

\begin{tabular}{lcccccccccccccc}
\hline & \multicolumn{4}{c}{ Control $(n=30)$} & \multicolumn{4}{c}{ MODS $(n=30)$} & \multicolumn{4}{c}{ DCQD $(n=30)$} & & \\
& ++ & + & \pm & - & ++ & + & \pm & - & ++ & + & \pm & - & \\
\hline Visions & 23 & 3 & 3 & 1 & 2 & 4 & 5 & 19 & 20 & 5 & 2 & 3 & 44.537 & 0.000 \\
\hline
\end{tabular}

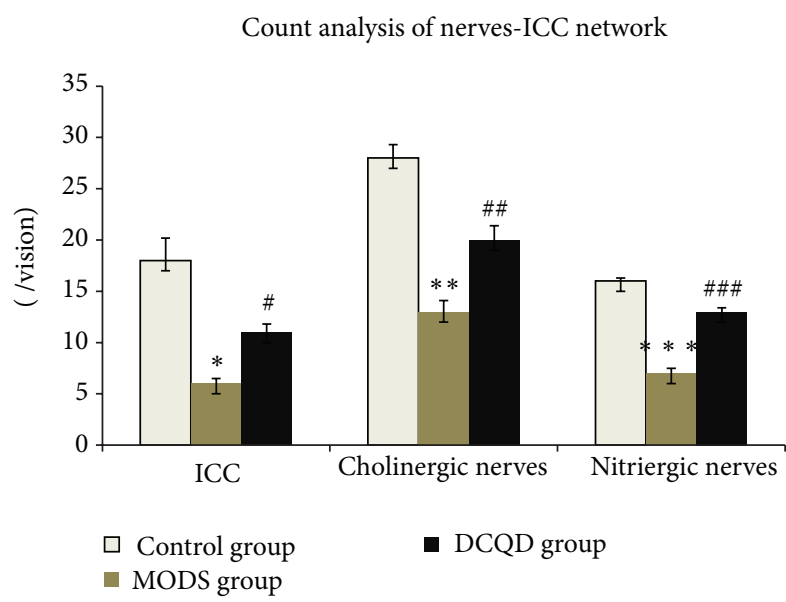

Figure 7: Count analysis of ICC, cholinergic nerve fibers, and nitrergic nerve fibers. Three specimens in each group and three high magnification visions in each specimen were observed randomly. Compared with control group, count analysis of ICC, $n=9,{ }^{*} t=$ 9.508, $P<0.01$; compared with control group, count analysis of cholinergic nerve fibers, $n=9,{ }^{* *} t=8.793, P<0.01$; compared with control group, count analysis of nitrergic nerve fibers, $n=9$, ${ }^{* * *} t=15.041, P<0.01$; compared with MODS group, count analysis of ICC, $n=9,{ }^{*} t=5.598, P<0.01$; compared with MODS group, count analysis of cholinergic nerve fibers, $n=9,{ }^{\# \#} t=3.670$, $P<0.01$; compared with MODS group, count analysis of nitrergic nerve fibers, $n=9,{ }^{\# \# \#} t=9.500, P<0.01$.

mainly located in circular muscularis and gaps between muscularis, especially intensively and evenly in outermost layer of circular muscularis and in the layer close to internal surface of mucosa, with little or no distribution in longitudinal muscularis.

MODS group (Figure 10(b)) shows immunoreactive products of $\mathrm{Cx} 43$ were mainly distributed in the cytomembrane and cytoplasm and were less than control group $(P<0.01)$. Moreover, we found that there was little or no distribution of $\mathrm{Cx} 43$ in small intestinal muscularis.

DCQD group (Figure 10(c)) shows immunoreactive products of $\mathrm{Cx} 43$ were more than MODS group $(P<0.01)$. Moreover, there was no significant difference, compared with control group.

According to Nemeth's [26] statistical criteria, the positive staining in cytomembrane and cytoplasm was tan. Immunoreactive products of $\mathrm{Cx} 43$ were divided into four grades by color density: (-) no staining (negative); $( \pm$ ) mild staining (weakly positive); (+) moderate staining (positive); $(++)$ rich staining (strong positive) (see Table 1$)$.

Six specimens in each group and five high magnification visions in each specimen were observed randomly. There was

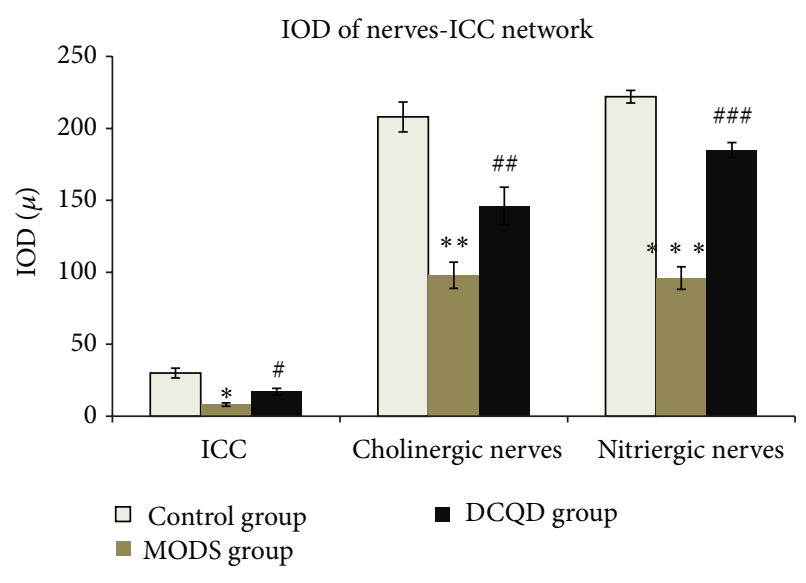

FIGURE 8: IOD of ICC, cholinergic nerve fibers, and nitrergic nerve fibers. Compared with control group, IOD of ICC, $n=9,{ }^{* *} t=$ 6.293, $P<0.01$; compared with control group, IOD of cholinergic nerve fibers, $n=9,{ }^{* *} t=8.032, P<0.01$; compared with control group, IOD of nitrergic nerve fibers, $n=9,{ }^{* * *} t=13.946, P<0.01$; compared with MODS group, IOD of ICC, $n=9,{ }^{*} t=3.851$, $P<0.01$; compared with MODS group, IOD of cholinergic nerve fibers, $n=9$, ${ }^{\# \#} t=2.999, P<0.01$; compared with MODS group, IOD of nitrergic nerve fibers, $n=9,{ }^{\# \# \#} t=9.349, P<0.01$.

difference between control group, MODS group, and DCQD group using Kruskal Wallis test, $H=44.537, P<0.05$; there was difference between control group and MODS group using Mann-Whitney test, $H=67.500, P<0.05$; there was difference between MODS group and DCQD group using Mann-Whitney test, $H=118.500, P<0.05$; there was no difference between control group and DCQD group using Mann-Whitney test, $H=393.500, P>0.05$.

3.6. Cx43 Using Transmission Electron Microscopy. Control group (Figures 11(a), 12(a), and 13(a)) shows there were gap junctions between ICC and ICC, ICC and SMC, SMC, and SMC. The distance was about $2 \mathrm{~nm}$. Many cylindrical combinations could be seen in gaps of ICC. We also found there were desmosomes junctions between ICC and ICC, ICC and SMC, and SMC and SMC, and the distance was about 25-30 $\mathrm{nm}$. There was middle dense band or middle line in desmosomes junctions and dense spot about $10 \mathrm{~mm}$ thick on the inside of plasma membrane. ENS-ICC-SMC network was integrated.

MODS group (Figures 11(b), 12(b), and 13(b)) shows there were no gap junctions between ICC and ICC, ICC and SMC, SMC and SMC, and the distance obviously widened. We also found chromatin condensation and aggregation. Moreover, mitochondria were obviously swelling, some were ruptured, 


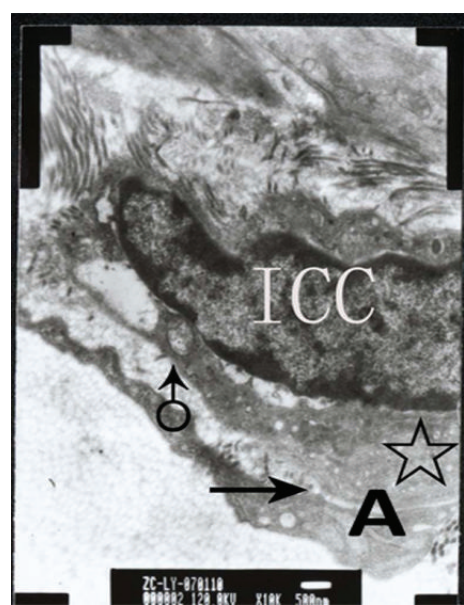

(a)

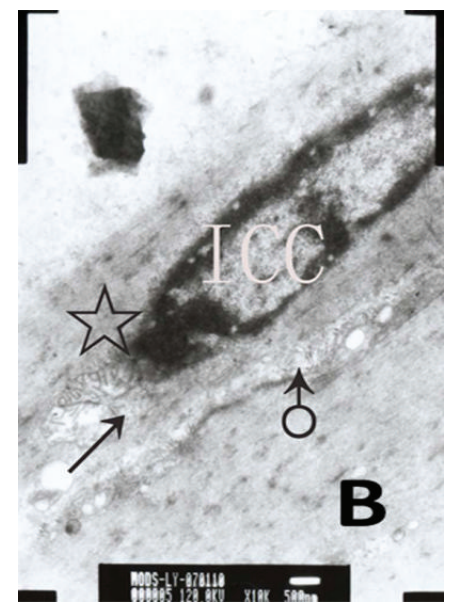

(b)

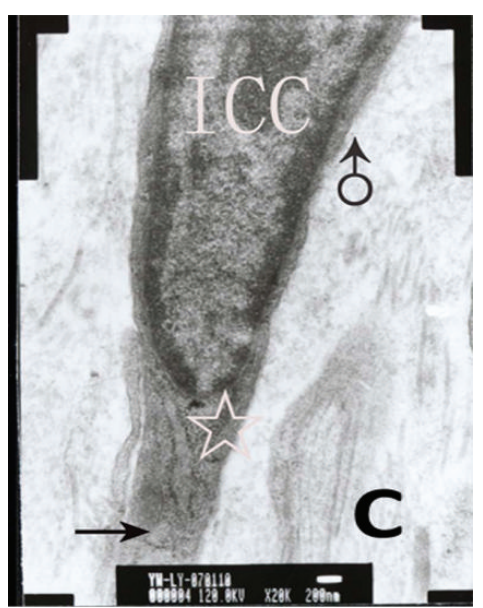

(c)

FIGURE 9: Ultrastructures of ICC-DMP using conventional electron microscopy. (a) Control group shows there were abundant mitochondria (ఓ) ), smooth endoplasmic reticulum, well-developed Golgi apparatus ( $\uparrow$ ), and intact basal membrane (đ) (ruler: $500 \mathrm{~nm}$ ); (b) MODS group shows nucleus shriveled and the number of organelles decreased significantly. Also, mitochondria (ઐ) were distorting and swelling, and Golgi apparatus ( $\uparrow$ ) was damaged. Moreover, basal membrane ( $₫$ ) was incomplete (ruler: $500 \mathrm{~nm}$ ); (c) DCQD group shows nucleus was normal. Also, mitochondria ( $\downarrow$ ) and Golgi apparatus $(\uparrow)$ were more than MODS group. Only a few mitochondria were swelling and a few endoplasmic reticula were dilated. Moreover, basal membrane ( $\widehat{0})$ was almost complete (ruler: $200 \mathrm{~nm}$ ).

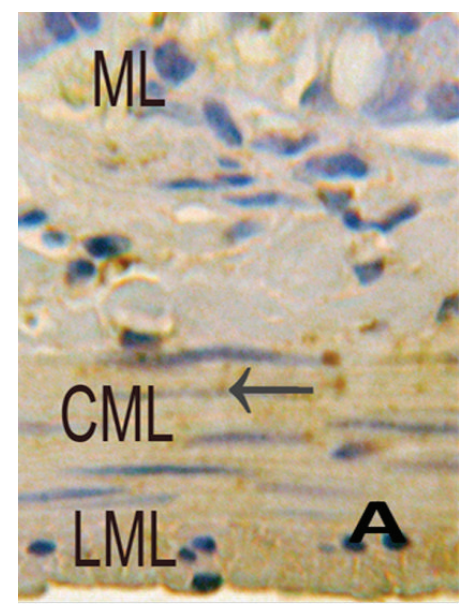

(a)

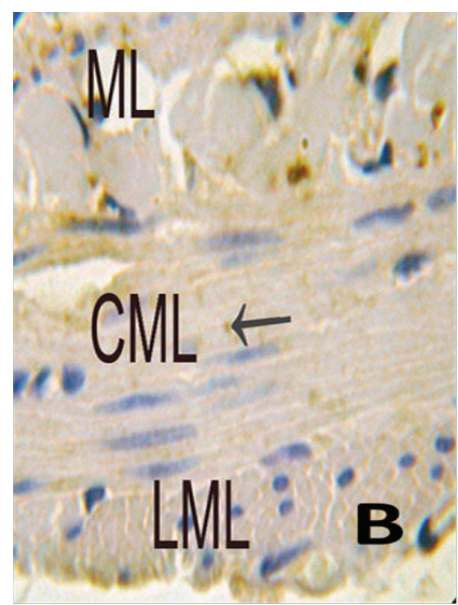

(b)

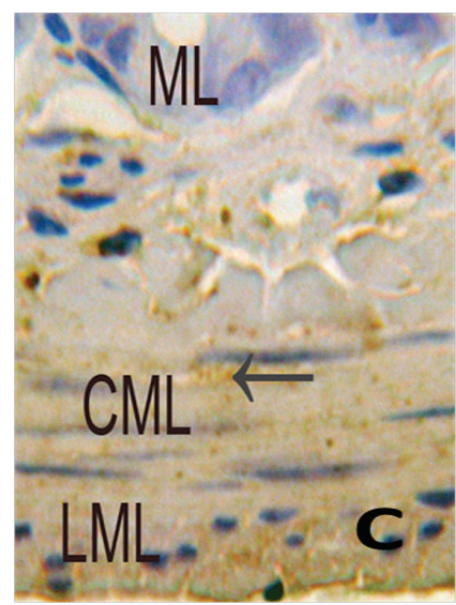

(c)

FIGURE 10: Immunohistochemistry of Cx43 using light microscopy. (a) Control group shows immunoreactive products of Cx43 ( $\leftarrow$ ) were tan and mainly located evenly in circular muscularis, little in longitudinal muscularis, and none in mucous layer (at magnification of 400 times); (b) MODS group shows immunoreactive products of $\mathrm{Cx} 43(\leftarrow)$ were tan and mainly located in circular muscularis, less than control group, none in longitudinal muscularis and mucous layer (at magnification of 400 times); (c) DCQD group shows immunoreactive products of Cx43 $(\leftarrow)$ were tan and mainly located evenly in circular muscularis, and there was no significant difference, compared with control group (at magnification of 400 times).

and cell membranes of ICC were oblique. ENS-ICC-SMC network was damaged significantly.

DCQD group (Figures 11(c), 12(c), and 13(c)) shows there were gap junctions between ICC and ICC, ICC and SMC, and SMC and SMC, and the distance was about $2 \mathrm{~nm}$. Also, some cylindrical combination could be seen in gaps of ICC. Moreover, there were more mitochondria in ICC than MODS group, and cell membranes of ICC were clear. Though some mitochondria were swelling, nearly no mitochondria were ruptured, and there was no chromatin aggregation. ENSICC-SMC network was integrated.

\section{Comment}

MODS is an extremely complex systemic response process with many causes. It is the most serious complication after trauma and infection and its mortality is very high. Currently, the leading view is that MODS develops from SIRS and compensatory anti-inflammatory response syndrome.

Studies have shown that gut is the key organ to originate and trigger SIRS and MODS [4, 5]. MODS may cause gut ischemia and anoxia, thus resulting in increase in gut permeability. Increased gut permeability is conducive to the 


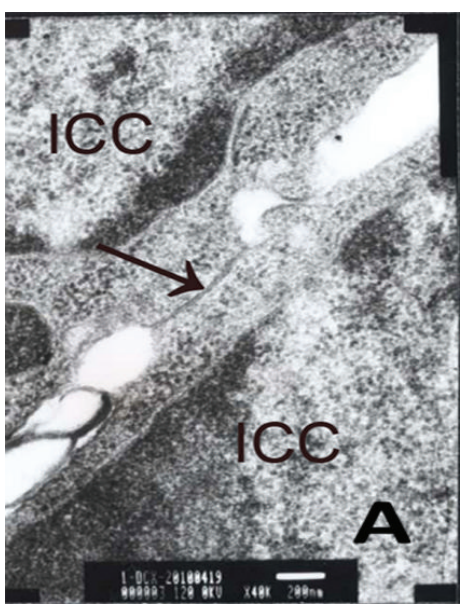

(a)

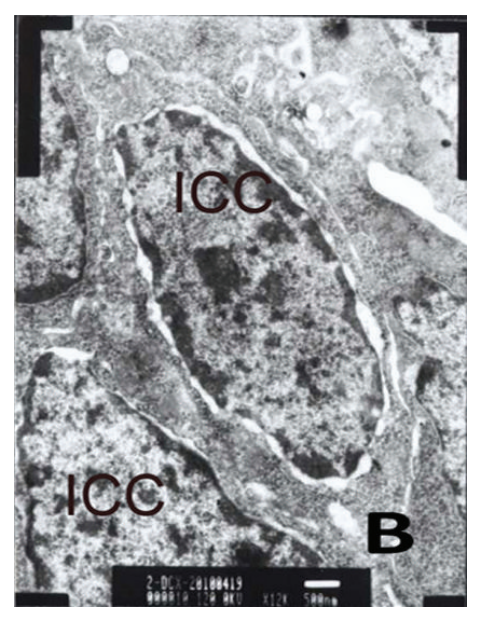

(b)

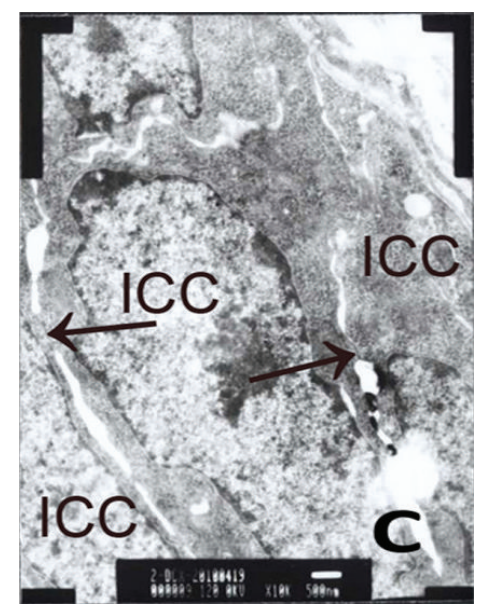

(c)

FIGURE 11: Cx43 between ICC and ICC using transmission electron microscopy. (a) Control group shows gap junction ( $\uparrow$ ) between ICC and ICC (ruler: $200 \mathrm{~nm}$ ); (b) MODS group shows no gap junction between ICC and IC and ICC membrane was not clear. Moreover, chromatin condensation and aggregation could be seen (ruler: $500 \mathrm{~nm}$ ); (c) DCQD group shows gap junction ( $\uparrow$ ) with intact structure between ICC and ICC. ICC nucleolus and cell membrane were clear. NO chromatin condensation and aggregation (ruler: $500 \mathrm{~nm}$ ).

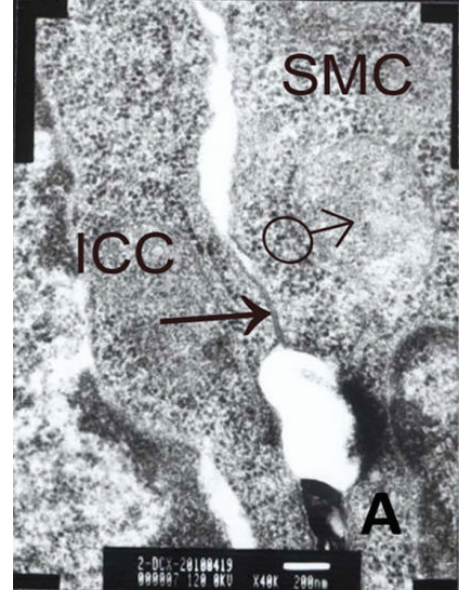

(a)

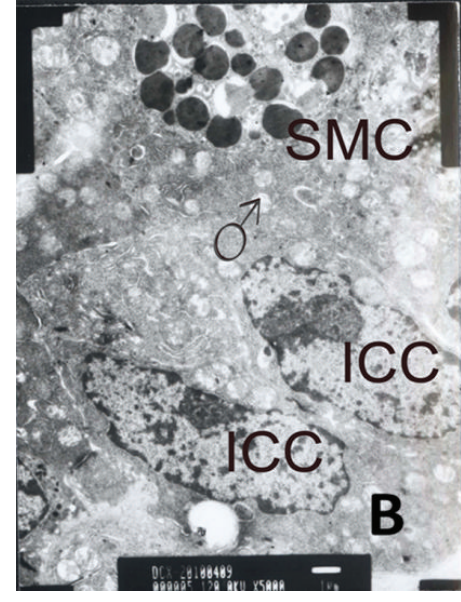

(b)

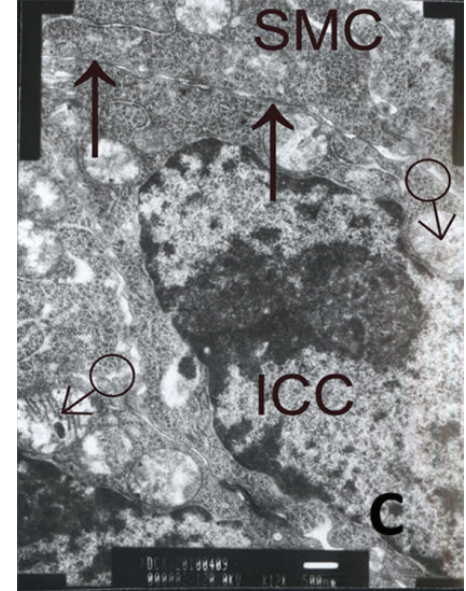

(c)

FIGURE 12: Cx43 between ICC and SMC using transmission electron microscopy. (a) Control group shows gap junction ( $\uparrow$ ) between ICC and SMC. Mitochondria (o) (ruler: $200 \mathrm{~nm}$ ); (b) MODS group shows no gap junction between ICC and SMC. Many swelling and damaged mitochondria ( $\overbrace{}^{*})$ in cell (ruler: $1 \mu \mathrm{m}$ ); (c)DCQD group shows gap junction $(\uparrow)$ with intact structure between ICC and SMC. Many mitochondria $(\overbrace{}^{\star})$, and though some were swelling, there were no ruptured mitochondria (ruler: $500 \mathrm{~nm})$.

translocation of bacteria and endotoxin that lead to the activation of the immune inflammatory system, which contribute to SIRS/MODS [27-29]. MODS may cause GI peristalsis weakened or disappeared, so the digestive and absorption processes are affected and the bacteria in gut are overgrown. Then they produce large volumes of gas and the pressure in gastrointestinal tract will be increased. If the condition is further exacerbated, it will lead to toxic enteroparalysis which contribute to SIRS/MODS. So, improving the recovery of GI motility could effectively prevent MODS from deteriorating to multiple organ failure $[8,9]$. But the pathogenesis of GI motility dysfunction in MODS is not fully understood. DCQD is compound preparation, composed of Rhubarb,
Mirabilite, Fructus Aurantii Immaturus, and Magnolia officinalis. DCQD has been in use as purgative for nearly two thousand years in China. Researchers have found it is very effective in promoting the recovery of GI motility [21-23], However, the mechanism is not fully understood. In this study, we try to investigate the pathogenesis of GI motility dysfunction in MODS and therapeutic mechanism of DCQD.

In traditional Chinese medicine, for adults, the common dosage of crude drug of DCQD is $36-72 \mathrm{~g}$. According to body surface area, we made dosage conversions between human and experimental rats, and for experimental rats, the dosage of crude drug of DCQD should be $0.38 \mathrm{~g} / 100 \mathrm{~g}-$ $0.76 \mathrm{~g} / 100 \mathrm{~g}$. But, in the preliminary experiment, we found 


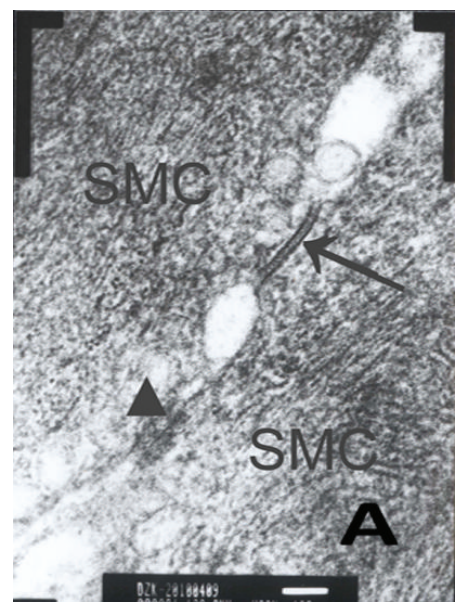

(a)

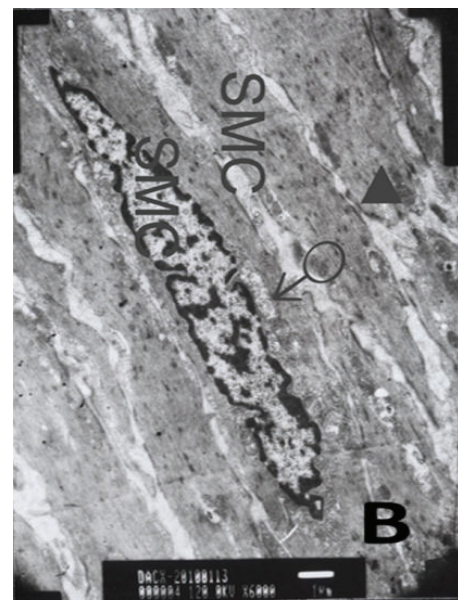

(b)

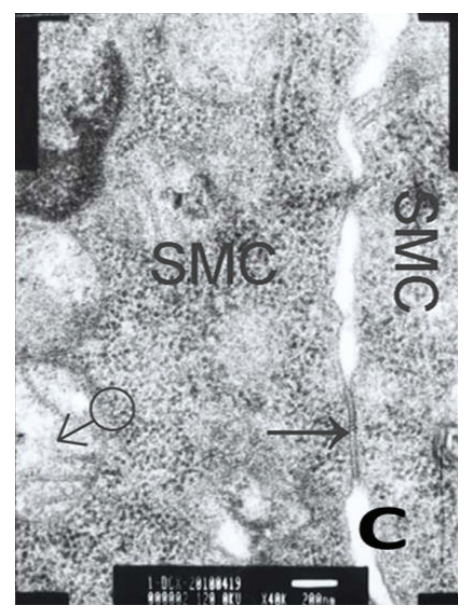

(c)

FIGURE 13: Cx43 between SMC and SMC using transmission electron microscopy. (a) Control group shows gap junction ( $\uparrow$ ) between SMC and SMC. Desmosomes junction $(\mathbf{\Lambda})$ between SMC and SMC. The distance was about 25-30 nm. There was also middle dense band or middle line in desmosomes junction and dense spot about $10 \mathrm{~mm}$ thick on the inside of plasma membrane (ruler: $100 \mathrm{~nm}$ ); (b) MODS group shows no gap junction between SMC and SMC, and chromatin condensation and aggregation could be seen in SMC. Some mitochondria ( $\left.{ }^{\star}\right)$ were swelling. There was desmosomes junction $(\boldsymbol{\Delta})$ between SMC and SMC, dense spots of one desmosomes junction were asymmetric, and no middle line (ruler: $1 \mu \mathrm{m}$ ); (c) DCQD group, gap junction $(\uparrow)$ with intact structure between SMC and SMC. There were many mitochondria $\left({ }^{\top}\right)$, and though some were swelling, there was no ruptured mitochondria. Moreover, cell membrane was clear (ruler: $\left.1 \mu \mathrm{m}\right)$.

that the best therapeutic dosage of DCQD to rats is $2 \mathrm{~g} / 100 \mathrm{~g}$ (two times/days, each time $1 \mathrm{~g} / 100 \mathrm{~g}$ ), and we thought that rats may have stronger tolerance to DCQD than human. So, we chose the dosage of $2 \mathrm{~g} / 100 \mathrm{~g}$.

ICC serve as the pacemaker cells of the GI tract and mediators of enteric motor neurotransmission. They play an important role in generating and regulating GI motility. ICC have been grouped according to either their localization in the muscle layers, their basic morphology (stellate and bipolar), or their primary function [30]. ICC of the myenteric plexus (ICC-MY) occur around the circumference of the myenteric plexus in the space between the circular and longitudinal muscularis. ICC-MY serve as electrical pacemakers, active propagation pathways for slow waves; intramuscular interstitial cells of Cajal (ICC-IM) are the cell types found in the circular and longitudinal muscularis, which connect to swollen gastrointestinal motor nerve endings and are located surrounding muscle fibers in parallel. ICC-IM serve as mediators of enteric neurotransmission; ICC-DMP are the cell types found in the deep muscular plexus in the space between the inner layers of circular muscle layers and the outer layers of circular muscle layers and serve as mediators of enteric neurotransmission; ICC of the submucosa (ICC$\mathrm{SM}$ ) are the cell types found in the submucosa and are now considered to serve as pacemakers.

Studies have shown that there are synaptic-like contacts that connect ICC to enteric nerves [26] and gap junctions that connect ICC to SMC [31]. ENS, ICC, and SMC connect to form a network structure, which is the basic functional unit of GI motility [10, 29, 32-35]. ICC-DMP are the primary target cells of nerve fibers and express many neurotransmitter receptors, for example, muscarine receptors (M2 and M3), somatostatin $2 \mathrm{~A}$ receptors, neurokinin receptors NK1 and
NK3, vasoactive intestinal peptide (VIP-R), and so forth [36]. These indicate ICC serve as mediators of neural signal transduction to SMC. Studies have shown that VAChT, P substance (SP), nNOS, and vasoactive intestinal peptide (VIP) positive nerve fibers connect closely to ICC, and these provide a morphological basis for ICC serving as mediators of neural signal transduction [37-39]. Studies have shown that, in some GI motility disorders diseases, there is abnormality or decrease in number of ICC $[15,16]$ or decrease of neurotransmission of ENS-ICC-SMC network [17-19].

Studies have shown that, the signal transduction between ICC and ICC, ICC and SMC, and SMC and SMC is mediated by gap junctions [32]. The main structures of gap junctions are connexons. Each connexon is made up of four or six connection proteins, and the $\mathrm{Cx} 43$ is the most important connection protein in GI tract whose expression was closely related to GI motility [40]. In many GI motility diseases, for example, diabetic gastroparesis, hypertrophic pyloric stenosis, and congenital megacolon, the expression of CX is abnormal [20].

ICC network, ENS-ICC-SMC network and gap junctions are related closely to GI motility, and there is GI motility dysfunction in MODS, but the study on changes of ICC network, ENS-ICC-SMC network, and gap junctions in MODS is still lacking.

According to the Nemeth's method [25], ICC could be detected by C-Kit immunofluorescence staining. In this study, the changes of ICC-DMP network in small intestine in MODS were investigated with c-Kit immunohistochemistry using confocal microscopy. The results showed that, in MODS group, the number of ICC was significantly decreased, the ICC network was damaged. 
In this study, the changes of ultrastructures of ICC-DMP in intestinal tissues in MODS were observed using electron microscopy. The results showed that ultrastructures of ICC were damaged significantly in MODS. The ultrastructural damages to ICC may be the main cause of morphological and functional damages to ICC. The possible causes of ultrastructural damages to ICC may be gut ischemia and anoxia, the release of a large number of inflammatory mediators, and so forth [41-48]. The damages to ultrastructures of ICC were repaired by DCQD.

The results above suggest that, in MODS, the damages to ultrastructures of ICC and ICC network would affect enteric neurotransmission and the contraction or relaxation of SMC and lead to GI motility dysfunction. DCQD could effectively repair the damages and promote the recovery of GI motility.

Cholinergic neurons are the largest number of neurons in ENS [49]. Acetyl choline (AchE) is a kind of excitatory neurotransmitter released by cholinergic nerves and plays an important role in regulation of GI motility [50-52]. In addition to the sympathetic and parasympathetic nerve, there are nonadrenergic and noncholinergic nerves in intestinal tissues, for example, peptidergic nerve and nitrergic nerve. NO released by nitrergic nerve lead to relaxation of enteric smooth muscle and has inhibitory effect on GI motility. According to the Nemeth's method [25], ICC could be detected by c-Kit immunofluorescence staining, and cholinergic/nitrergic nerve could be detected by VAChT/nNOS immunofluorescence staining.

In this study, the changes of enteric nerves-ICC network in intestinal tissues in MODS were observed with double immunofluorescence staining of VAChT/nNOS and c-Kit using confocal microscopy. The results showed that the numbers of ICC and cholinergic/nitrergic nerve fibers were decreased significantly, the connections between nerves and ICC were reduced or disappeared, and nerves-ICC network integrity was damaged significantly in MODS group. The numbers of ICC and cholinergic/nitrergic nerve fibers were increased and the damages to connections were repaired in DCQD group.

In this study, the changes of ultrastructures of enteric nerves-ICC network in intestinal tissues in MODS were observed using electron microscopy. The results showed that ultrastructures of ICC and the connections between cholinergic/nitrergic nerves and ICC, ICC and ICC, and ICC and SMC were damaged significantly in MODS group. The damages were repaired in DCQD group.

The results above suggest that, in MODS, the damages to ENS-ICC-SMC network in part may be the reason of GI motility dysfunction. DCQD could effectively repair the damages and maintain integrity of the ICC network and ENSICC-SMC network, so it could promote the recovery of GI motility.

In this study, we observed the changes of expression of Cx43 in intestinal tissues in MODS using light microscopy and transmission electron microscopy, for qualitative, semiquantitative and quantitative analysis of $\mathrm{Cx} 43$. The results of immunohistochemistry showed, in MODS group, Cx43 in intestinal tissues was decreased significantly and distribution of Cx43 was not even. Gap junctions between ICC and
ICC, ICC and SMC, and SMC and SMC were decreased or disappeared using transmission electron microscopy. In DCQD group, Cx43 was increased significantly and damages to gap junctions were repaired.

The results above suggest that, in MODS, decrease in numbers of gap junctions, destruction of the structure, and decline in function will affect signal transduction between ICC and ICC, ICC and SMC, and SMC and SMC. Then they will affect generation and transmission of slow wave and affect contractive function of smooth muscle, and the electrical excitation between smooth muscle cells cannot spread rapidly. These will lead to GI motility dysfunction. DCQD could effectively repair the damages to gap junctions and promote the recovery of GI motility.

Studies have shown that DCQD has anti-inflammation effect $[53,54]$. The therapeutic effect of DCQD in MODS may be due to its anti-inflammation effect. But, the exact mechanism of different types of ICC in the GI motility is not fully understood, physiopathological change of ENS-ICCSMC network in MODS is complicated, and mechanism of DCQD therapy may be multicomponent and multitarget. It remains to be further investigated.

\section{Conclusion}

The pathogenesis of GI motility dysfunction in MODS in part may be due to the damages to enteric nerves-ICC-SMC network and gap junctions. The therapeutic mechanism of DCQD in part may be that it could repair the damages and maintain the integrity of enteric nerves-ICC-SMC network.

\section{Conflict of Interests}

The authors declare that there is no conflict of interests regarding the publication of this paper.

\section{Acknowledgment}

This work was supported by the National Natural Science Foundation of China (no. 30572449).

\section{References}

[1] D. E. Fry, L. Pearlstein, R. L. Fulton, and H. C. Polk Jr., "Multiple system organ failure. the role of uncontrolled infection," Archives of Surgery, vol. 115, no. 2, pp. 136-140, 1980.

[2] M. M. Levy, M. P. Fink, J. C. Marshall et al., "2001 SCCM/ESICM/ACCP/ATS/SIS international sepsis definitions conference," Critical Care Medicine, vol. 31, no. 4, pp. 1250-1256, 2003.

[3] T. B. Hackett, "Introduction to multiple organ dysfunction and failure," Veterinary Clinics of North America: Small Animal Practice, vol. 41, no. 4, pp. 703-707, 2011.

[4] G. M. Swank and E. A. Deitch, "Role of the gut in multiple organ failure: bacterial translocation and permeability changes," World Journal of Surgery, vol. 20, no. 4, pp. 411-417, 1996.

[5] R. Mittal and C. M. Coopersmith, "Redefining the gut as the motor of critical illness," Trends in Molecular Medicine, vol. 20, no. 4, pp. 214-223, 2014. 
[6] H. T. Hassoun, B. C. Kone, D. W. Mercer, F. G. Moody, N. W. Weisbrodt, and F. A. Moore, "Post-injury multiple organ failure: the role of the gut," Shock, vol. 15, no. 1, pp. 1-10, 2001.

[7] K. Shimizu, H. Ogura, T. Asahara et al., "Probiotic/synbiotic therapy for treating critically ill patients from a gut microbiota perspective," Digestive Diseases and Sciences, vol. 58, no. 1, pp. 23-32, 2013.

[8] F. Puleo, M. Arvanitakis, A. van Gossum, and J.-C. Preiser, "Gut failure in the ICU," Seminars in Respiratory and Critical Care Medicine, vol. 32, no. 5, pp. 626-638, 2011.

[9] J. J. Meier, "Waking up the gut in critically ill patients," Critical Care, vol. 14, no. 5, article 183, 2010.

[10] S. M. Ward, K. M. Sanders, and G. D. S. Hirst, "Role of interstitial cells of Cajal in neural control of gastrointestinal smooth muscles," Neurogastroenterology and Motility, vol. 16, no. 1, pp. 112-117, 2004.

[11] T. Schultz, V. Daniel, and E. E. Daniel, "Does ICC pacing require functional gap junctions between ICC and smooth muscle in mouse intestine?" Neurogastroenterology \& Motility, vol. 15, no. 2, pp. 129-138, 2003.

[12] S. E. Carbone, D. A. Wattchow, N. J. Spencer, and S. J. H. Brookes, "Loss of responsiveness of circular smooth muscle cells from the guinea pig ileum is associated with changes in gap junction coupling," The American Journal of PhysiologyGastrointestinal and Liver Physiology, vol. 302, no. 12, pp. G1434-G1444, 2012.

[13] G. Söhl and K. Willecke, "Gap junctions and the connexin protein family," Cardiovascular Research, vol. 62, no. 2, pp. 228232, 2004.

[14] G. Meşe, G. Richard, and T. W. White, "Gap junctions: basic structure and function," Journal of Investigative Dermatology, vol. 127, no. 11, pp. 2516-2524, 2007.

[15] I. Takayama, Y. Daigo, S. M. Ward, K. M. Sanders, T. Yamanaka, and M. A. Fujino, "Differential gene expression in the small intestines of wildtype and $W / W^{V}$ mice," Neurogastroenterology and Motility, vol. 13, no. 2, pp. 163-168, 2001.

[16] M. Müller, S. Colcuc, D. G. Drescher et al., "Murine genetic deficiency of neuronal nitric oxide synthase $\left(\mathrm{nNOS}^{-/-}\right)$and interstitial cells of Cajal (W/W $\left.\mathrm{W}^{v}\right)$ : implications for achalasia?" Journal of Gastroenterology and Hepatology, vol. 29, no. 10, pp. 1800-1807, 2014.

[17] R. Farré, X. Y. Wang, E. Vidal et al., "Interstitial cells of Cajal and neuromuscular transmission in the rat lower oesophageal sphincter," Neurogastroenterology and Motility, vol. 19, no. 6, pp. 484-496, 2007.

[18] J. I. Lee, H. Park, M. A. Kamm, and I. C. Talbot, "Decreased density of interstitial cells of Cajal and neuronal cells in patients with slow-transit constipation and acquired megacolon," Journal of Gastroenterology and Hepatology, vol. 20, no. 8, pp. 12921298, 2005.

[19] S. M. Ward, E. A. Beckett, X. Wang, F. Baker, M. Khoyi, and K. M. Sanders, "Interstitial cells of Cajal mediate cholinergic neurotransmission from enteric motor neurons," The Journal of Neuroscience, vol. 20, no. 4, pp. 1393-1403, 2000.

[20] L. Nemeth, S. Maddur, and P. Puri, "Immunolocalization of the Gap junction protein Connexin43 in the interstitial cells of Cajal in the normal and Hirschsprung's disease bowel," Journal of Pediatric Surgery, vol. 35, no. 6, pp. 823-828, 2000.

[21] T. Suo, X. Gu, R. Andersson et al., "Oral traditional Chinese medication for adhesive small bowel obstruction," Cochrane Database of Systematic Reviews, vol. 5, Article ID CD008836, 2012.
[22] W. Jian, L. Heng, and Q. Q. Hui, "Effect of Da-Cheng-Qi-Tang on gastrointestinal motility in patients undergoing laparotomy," Hepato-Gastroenterology, vol. 58, no. 112, pp. 1887-1892, 2011.

[23] Q. H. Qi, J. Wang, G. G. Liang, and X. Z. Wu, "Da-ChengQi-Tang promotes the recovery of gastrointestinal motility after abdominal surgery in humans," Digestive Diseases and Sciences, vol. 52, no. 6, pp. 1562-1570, 2007.

[24] Z. S. Hu, Z. Y. Sheng, L. B. Xue et al., "A serilized studies of animal models of posttraumatic multiple organ dysfunction syndrome," Medical Journal of Chinese People's Liberation Army, vol. 21, no. 1, pp. 5-9, 1996 (Chinese).

[25] L. Nemeth and P. Puri, "Three-dimensional morphology of cKit-positive cellular network and nitrergic innervation in the human gut," Archives of Pathology \& Laboratory Medicine, vol. 125, no. 7, pp. 899-904, 2001.

[26] X. Y. Wang, K. M. Sanders, and S. M. Ward, "Intimate relationship between interstitial cells of Cajal and enteric nerves in the guinea-pig small intestine," Cell and Tissue Research, vol. 295, no. 2, pp. 247-256, 1999.

[27] G. Ackland, M. P. Grocott, and M. G. Mythen, "Understanding gastrointestinal perfusion in critical care: so near, and yet so far," Critical Care, vol. 4, no. 5, pp. 269-281, 2000.

[28] E. A. Deitch, "Gut-origin sepsis: evolution of a concept," Surgeon, vol. 10, no. 6, pp. 350-356, 2012.

[29] G. A. Nieuwenhuijzen and R. J. Goris, "The gut: the "motor" of multiple organ dysfunction syndrome?" Current Opinion in Clinical Nutrition \& Metabolic Care, vol. 2, no. 5, pp. 399-404, 1999.

[30] M. Hanani and H. R. Freund, "Interstitial cells of Cajal-their role in pacing and signal transmission in the digestive system," Acta Physiologica Scandinavica, vol. 170, no. 3, pp. 177-190, 2000.

[31] P. Yang, S. Wang, J. A. Gandahi et al., "Ultrastructural identification of different subtypes of interstitial cells of Cajal in the chicken ileum," Poultry Science, vol. 91, no. 8, pp. 1936-1940, 2012.

[32] E. E. Daniel, "Communication between interstitial cells of Cajal and gastrointestinal muscle," Neurogastroenterology and Motility, vol. 16, no. 1, pp. 118-122, 2004.

[33] X.-Y. Wang, C. Paterson, and J. D. Huizinga, "Cholinergic and nitrergic innervation of ICC-DMP and ICC-IM in the human small intestine," Neurogastroenterology \& Motility, vol. 15, no. 5, pp. 531-543, 2003.

[34] T. Yamamoto, K. Watabe, M. Nakahara et al., "Disturbed gastrointestinal motility and decreased interstitial cells of Cajal in diabetic db/db mice," Journal of Gastroenterology and Hepatology, vol. 23, no. 4, pp. 660-667, 2008.

[35] I. Takayama, K. Horiguchi, Y. Daigo, T. Mine, M. Fujino, and S. Ohno, "The interstitial cells of Cajal and a gastroenteric pacemaker system," Archives of Histology and Cytology, vol. 65, no. 1, pp. 1-26, 2002.

[36] A. Epperson, W. J. Hatton, B. Callaghan et al., "Molecular markers expressed in cultured and freshly isolated interstitial cells of Cajal," American Journal of Physiology-Cell Physiology, vol. 279, no. 2, pp. C529-C539, 2000.

[37] K. Horiguchi, K. M. Sanders, and S. M. Ward, "Enteric motor neurons form synaptic-like junctions with interstitial cells of Cajal in the canine gastric antrum," Cell and Tissue Research, vol. 311, no. 3, pp. 299-313, 2003.

[38] S. Iino, S. M. Ward, and K. M. Sanders, "Interstitial cells of Cajal are functionally innervated by excitatory motor neurones in the murine intestine," Journal of Physiology, vol. 556, no. 2, pp. 521$530,2004$.

[39] C. A. Cobine, G. W. Hennig, M. Kurahashi, K. M. Sanders, S. M. Ward, and K. D. Keef, "Relationship between interstitial cells 
of Cajal, fibroblast-like cells and inhibitory motor nerves in the internal anal sphincter," Cell and Tissue Research, vol. 344, no. 1, pp. 17-30, 2011.

[40] R. Rutkowski, B. Kosztyła-Hojna, L. Kańczuga-Koda, M. Sulkowska, S. Sulkowski, and K. Rutkowski, "Structure and physiological function of connexin proteins," Postępy Higieny $i$ Medycyny Doświadczalnej, vol. 62, pp. 632-641, 2008.

[41] H. Zhou, J. Gao, W. Wu et al., "Octreotide ameliorates intestinal dysmotility by interstitial cells of cajal protection in a rat acute necrotizing pancreatitis model," Pancreas, vol. 40, no. 8, pp. 1226-1233, 2011.

[42] M. Bettolli, C. De Carli, D. Cornejo-Palma et al., "Interstitial cell of Cajal loss correlates with the degree of inflammation in the human appendix and reverses after inflammation," Journal of Pediatric Surgery, vol. 47, no. 10, pp. 1891-1899, 2012.

[43] S. M. Ward, T. Ördög, S. D. Koh et al., "Pacemaking in interstitial cells of Cajal depends upon calcium handling by endoplasmic reticulum and mitochondria," Journal of Physiology, vol. 525, no. 2, pp. 355-361, 2000.

[44] H. Zhou, L. Liu, Y. Bai et al., "Damage of the interstitial cells of Cajal and myenteric neurons causing ileus in acute necrotizing pancreatitis rats," Surgery, vol. 149, no. 2, pp. 262-275, 2011.

[45] T. Suzuki, K.-J. Won, K. Horiguchi et al., "Muscularis inflammation and the loss of interstitial cells of Cajal in the endothelin ETB receptor null rat," The American Journal of PhysiologyGastrointestinal and Liver Physiology, vol. 287, no. 3, pp. G638G646, 2004.

[46] X.-Y. Wang, I. Berezin, H. B. Mikkelsen et al., "Pathology of interstitial cells of Cajal in relation to inflammation revealed by ultrastructure but not immunohistochemistry," The American Journal of Pathology, vol. 160, no. 4, pp. 1529-1540, 2002.

[47] E. Ekblad, R. Sjuve, A. Arner, and F. Sundler, "Enteric neuronal plasticity and a reduced number of interstitial cells of Cajal in hypertrophic rat ileum," Gut, vol. 42, no. 6, pp. 836-844, 1998.

[48] K. Altdorfer, G. Bagaméri, T. Donáth, and E. Fehér, "Nitric oxide synthase immunoreactivity of interstitial cells of Cajal in experimental colitis," Inflammation Research, vol. 51, no. 12, pp. 569-571, 2002.

[49] H. Kobayashi, Z. Li, A. Yamataka et al., "Acetylcholinesterase distribution and refractory constipation-a new criterion for diagnosis and management," Pediatric Surgery International, vol. 18, no. 5-6, pp. 349-353, 2002.

[50] K. Nishiyama, Y.-T. Azuma, S. Kita et al., " $\mathrm{Na}^{+} / \mathrm{Ca}^{2+}$ exchanger 1/2 double-heterozygote knockout mice display increased nitric oxide component and altered colonic motility," Journal of Pharmacological Sciences, vol. 123, no. 3, pp. 235-245, 2013.

[51] H. Suzuki, S. M. Ward, Y. R. Bayguinov, F. R. Edwards, and G. D. S. Hirst, "Involvement of intramuscular interstitial cells in nitrergic inhibition in the mouse gastric antrum," The Journal of Physiology, vol. 546, part 3, pp. 751-763, 2003.

[52] T. G. Dinan, L. V. Scott, D. Brady, D. McNamara, and P. W. N. Keeling, "Altered hypothalamic cholinergic responses in patients with nonulcer dyspepsia: a study of pyridostigminestimulated growth hormone release," The American Journal of Gastroenterology, vol. 97, no. 8, pp. 1937-1940, 2002.

[53] J. Zhao, J. Chen, W. Tang, L. Wan, W. Xiong, and L. Zhou, "Effect of Da-Cheng-Qi decoction on pancreatitis-associated lung injury in patients and anti-inflammatory responses in rat models," Pharmaceutical Biology, vol. 49, no. 10, pp. 1058-1064, 2011.

[54] S. H. Cao and J. D. Wang, "Immunomodulative effect of Dachengqi granule in treatment of multiple organ dysfunction syndrome," Chinese Journal of Trauma, vol. 20, no. 12, pp. 720 723, 2004 (Chinese). 


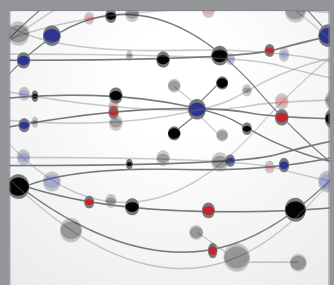

The Scientific World Journal
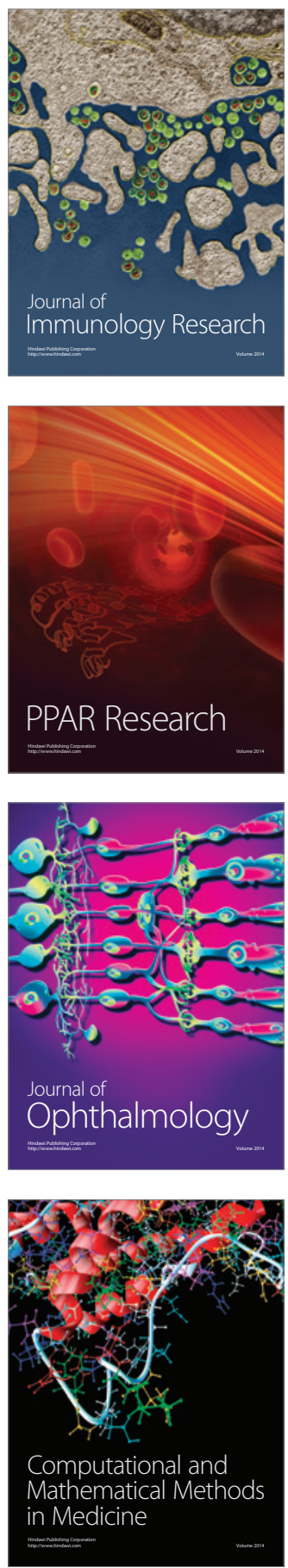

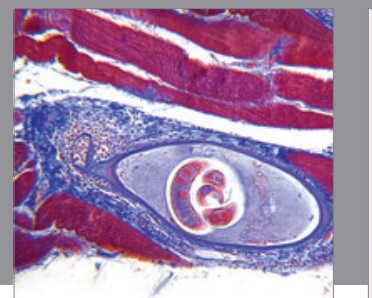

Gastroenterology

Research and Practice
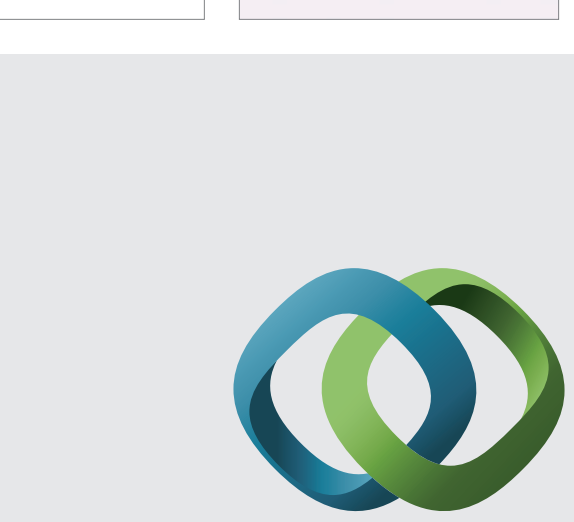

\section{Hindawi}

Submit your manuscripts at

http://www.hindawi.com
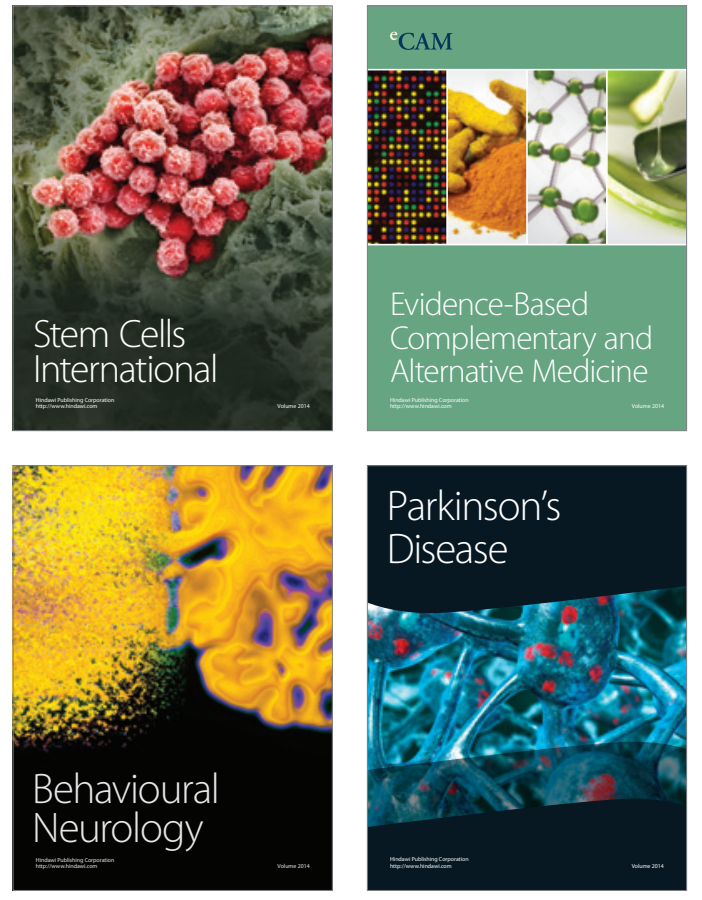
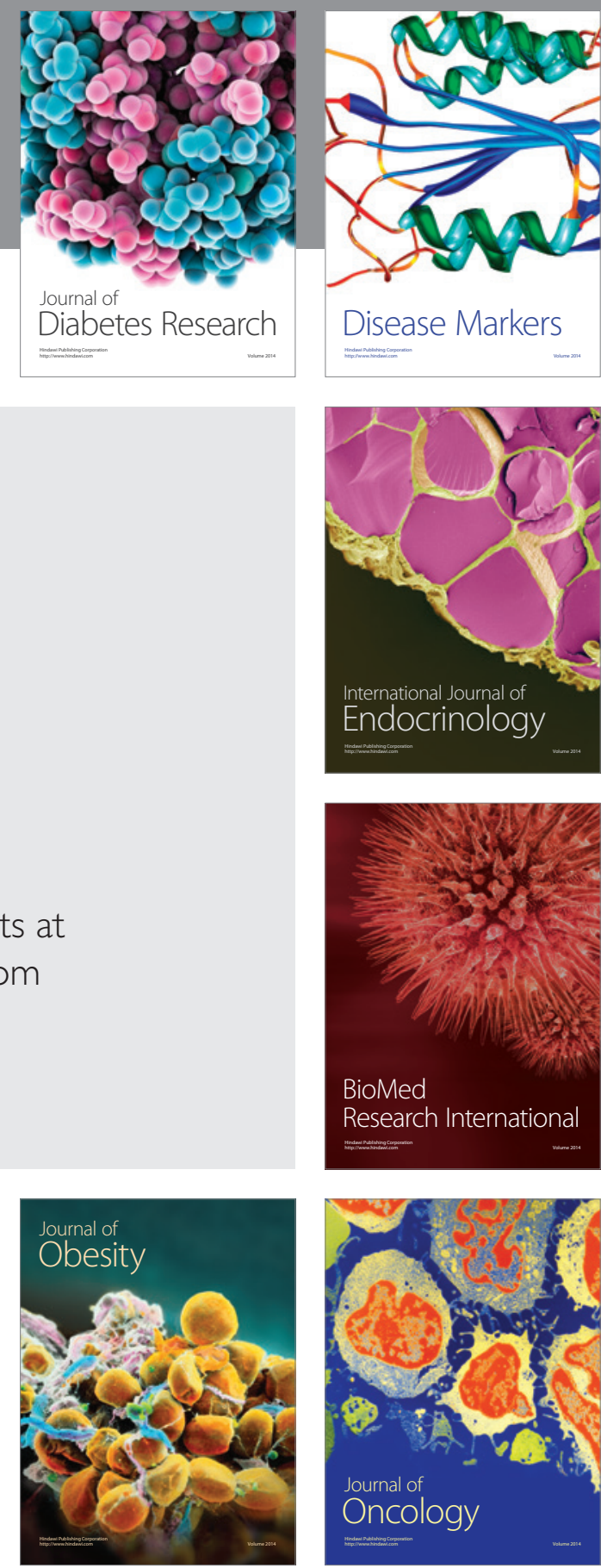

Disease Markers
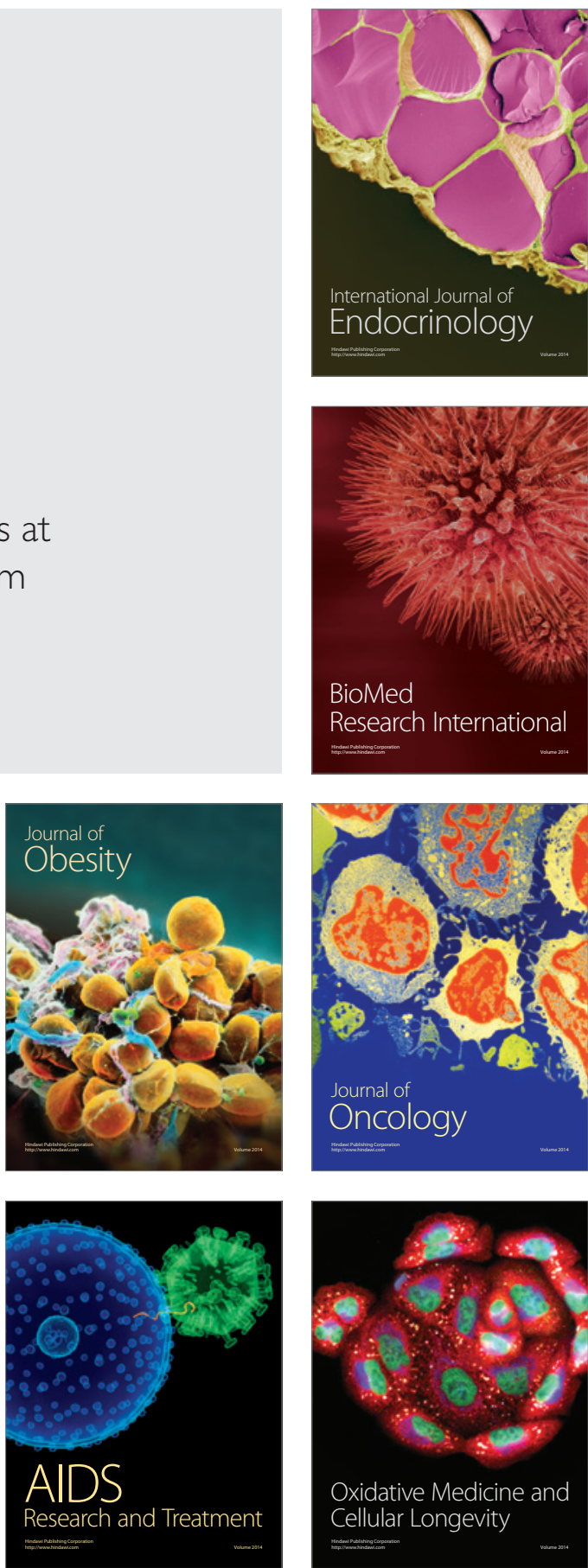